\title{
Efeitos da citocinina benzilaminopurina na estaquia da pitaia
}

\author{
Fábio Ferreira CRUVINEL ${ }^{1}$, Marco Antonio da Silva VASCONCELLOS ${ }^{1^{*}}$, \\ Luiz Aurélio Peres MARTELLETO ${ }^{1}$
}

\author{
${ }^{1}$ Departamento de Fitotecnia, Instituto de Agronomia, Universidade Federal Rural do Rio de Janeiro, Seropédica, RJ, Brasil. \\ *E-mail: fabiofcruvinel@uol.com.br
}

Recebido em fevereiro/2018; Aceito em agosto/2018.

\begin{abstract}
RESUMO: O interesse na fruta pitaia tem crescido nos últimos 20 anos e estudos sobre a propagação e uso de fitorreguladores nesta cultura são incipientes. Este trabalho teve como objetivo estudar o efeito da aplicação de 6-Benziloaminopurina (BAP) na estaquia da pitaia. O experimento foi conduzido na Casa de Vegetação de Propagação do Departamento de Fitotecnia da Universidade Federal Rural do Rio de Janeiro. Em delineamento fatorial inteiramente casualizado (DIC) com 2 formas de inoculação (imersão e Aplicação em corte no ápice da estaca) e 4 doses de BAP (0,50,100 e $\left.150 \mathrm{mg} \mathrm{L}^{-1}\right)$. Foram avaliados os dados de Sobrevivência (S), o Número de brotações Emitidas (NB), a Soma do Comprimento das Brotações (CB), a Massa Fresca (MFB) e Seca das Brotações (MSB) aos 100 dias após o plantio das estacas (DAP) e o efeito na Rebrota aos 200 dias (DAP). Houve sobrevivência de $100 \%$. Verificou-se um padrão linear crescente no incremento de NB por dose de BAP, e um padrão quadrático para as avaliações de CB, MFB e MSB com ponto máximo de $80 \mathrm{mg} \mathrm{L}^{-1}$ de BAP. Nenhum efeito significativo foi observado nos dados da Rebrota.
\end{abstract}

Palavras-chave: Hylocereus undatus, propagação, citocinina.

\section{Effects of cytokinin benzylaminopurine in pitaya cuttings}

\begin{abstract}
The interest in the pitaya has grown in the last 20 years and studies on the dragon fruit propagation and use of phytorregulators are incipient. This work aimed to study the effect of application of 6Benzyloaminopurine (BAP) on pitaya cuttings. The experiment was conducted at the Propagation Vegetation House of the Crop Science Department of the Federal Rural of Rio de Janeiro University. In completely randomized factorial design (DIC) with 2 forms of inoculation (immersion and Application in cut at the apex of the stakes) and 4 doses of BAP (0, 50, 100 and $\left.150 \mathrm{mg} \mathrm{L}^{-1}\right)$. The data of Survival (S), Number of sprouted shoots (NB), Sprouting length (CB), Fresh mass (MFB) and Sprout drying (MSB) were evaluated at 100 days after planting the cuttings (DAP) and the effect on regrowth (Rebrota) at 200 days (DAP). There was $100 \%$ survival. There was a linear pattern in the increase of NB per dose of BAP, and a quadratic pattern for the evaluations of $\mathrm{CB}, \mathrm{MFB}$ and MSB with maximum point of $80 \mathrm{mg} \mathrm{L}^{-1}$ of BAP. No significant effect was observed in the data from regrowth.
\end{abstract}

Keywords: Hylocereus undatus, propagation, cytokinin.

\section{INTRODUÇÃO}

A demanda por alimentos nutritivos e funcionais incrementou-se nos últimos anos e a fruta pitaia (Hylocereus sp) neste contexto destaca-se por seu sabor, digestibilidade, teor de nutrientes e ação antioxidante (FERRERES et al., 2017). O interesse por essa frutífera tem crescido por causa da rusticidade no seu cultivo, baixa demanda hídrica, boa aceitação e preço de seus frutos no mercado (MIZRAHI, 2014).

A pitaieira é um cacto epífito que ocorre naturalmente sob as copas das árvores e sobre rochedos em diversos biomas da América Latina. Os frutos podem ser consumidos in natura ou processados na forma de geleias, doces, sucos, sorvetes. A casca pigmentada tem sido estudada com grande potencial de utilização na indústria alimentícia (ORTIZ-HERNANDEZ; CARRILLO-SALAZAR, 2012; MIZRAHI, 2014).

A estaquia é o método mais utilizado na produção de mudas de pitaia. Neste método retiram-se cladódios inteiros ou segmentados e estaqueiam-se em substrato para induzir o enraizamento. Essa técnica de propagação proporciona selecionar materiais produtivos, pois as mudas formadas são clones da planta matriz e mudas produzidas por essa técnica apresentam menor tempo para a primeira produção de frutos (MARQUES et al., 2012; NUNES et al., 2014).

Pesquisas no Brasil relatam a utilização de fitorreguladores para aperfeiçoar e acelerar o processo de produção de mudas de pitaia por estaquia principalmente os de efeitos auxínicos na produção de raízes adventícias (PONTES FILHO et al., 2014; ALMEIDA et al., 2016). Esses autores citam a eficiência do ácido indolbutírico (AIB) neste processo de rizogênese das pitaieiras.

As citocininas são substâncias orgânicas que estimulam a citocinese. Nas plantas são produzidas nas raízes, embriões e frutos e transportadas a outras partes do vegetal. As citocininas naturais e sintéticas são utilizadas na cultura de tecidos vegetais para indução de brotações em diversas culturas. Na propagação ex vitro é utilizada com sucesso em várias espécies: na propagação rápida de bananeiras, várias ornamentais e na produção de mudas florestais (BOTIN; CARVALHO, 2015). Estudos dos efeitos de citocininas na 
propagação de pitaias concentram-se no uso da cultura de tecidos in vitro (VIÑAS et al., 2012; MENEZES et al., 2012; FAN et al., 2013; HUA et al., 2015). O uso e efeito de citocinina na indução de brotações na estaquia de cactáceas é pouco relatado (ORTIZ-HERNANDEZ; CARRILOSALAZAR, 2012; NUNES et al.,2014; ALMEIDA et al., 2016).

Este trabalho teve como objetivo avaliar o efeito da aplicação da citocinina sintética 6-Benzil-aminopurina (BAP) na indução e crescimento inicial de brotações em pitaia propagadas por estaquia.

\section{MATERIAL E MÉTODOS}

\subsection{Local do experimento}

O experimento foi conduzido em casa de vegetação no Setor de Olericultura do Departamento de Fitotecnia, do Instituto de Agronomia da Universidade Federal Rural do Rio de Janeiro, localizado no município de Seropédica-RJ, com 33 $\mathrm{m}$ de altitude, situado a $22^{\circ} 45^{\prime} \mathrm{S}, 43^{\circ} 41^{\prime} \mathrm{W}$. O clima da região é do tipo Aw, segundo a classificação de Köppen. O experimento foi implantado dia 10 de outubro de 2015.

\subsection{Material vegetal}

Cladódios de pitaia (Hylocereus undatus) foram selecionados de plantas matrizes em boas condições sanitárias aparentes provenientes da Fazendinha Agroecológica em Seropédica-RJ. Segmentaram-se os cladódios de $7 \pm 2 \mathrm{~cm}$ de diâmetro em estacas de $20 \mathrm{~cm}$ de comprimento.

\subsection{Preparo da solução de BAP}

As soluções de BAP marca VETEC, foram preparadas no Laboratório de Cultura de Tecidos Vegetais do Departamento de Fitotecnia da UFRRJ e calibradas nas concentrações de 0 , 50,100 e $150 \mathrm{mg}$. L ${ }^{-1}$ em água destilada com adição de cinco gotas de $\mathrm{NaOH}(1 \mathrm{M})$ para facilitar a diluição.

2.4. Preparo do canteiro e substrato

O experimento foi conduzido em canteiro com dimensões de 3,0 metros (m) de comprimento, 0,80 m de largura e 0,30 $\mathrm{m}$ de profundidade. $\mathrm{O}$ canteiro foi preenchido com substrato contendo areia misturada a esterco bovino na proporção 1:1 em volume. Foi realizada a análise de macronutrientes presentes no substrato utilizando a metodologia empregada por Antunes et al. (2016). O substrato apresentou 61,1 g. $\mathrm{Kg}^{-1}$ de Carbono Orgânico (C), 2,2 $\mathrm{g} \mathrm{Kg}^{-1}$ de nitrogênio $(\mathrm{N}), 0,83$ g. $\mathrm{Kg}^{-1}$ de Fósforo (P), 1,17 g. $\mathrm{Kg}^{-1}$ de Potássio (K), 1,51 g. $\mathrm{Kg}^{-}$ ${ }^{1}$ de Cálcio (Ca) , 1,63 g. $\mathrm{Kg}^{-1}$ de Magnésio (Mg).

Utilizando a mesma metodologia foi feita a análise física do substrato que apresentou Densidade Aparente de 1070 Kg.m ${ }^{-3}$, Densidade de Partículas de 2470 Kg.m ${ }^{-3}$, Microporosidade de 49,65\%, Macroporosidade de 6,92\% e Capacidade de Retenção de Água de 49,65 mL.50. $\mathrm{cm}^{-3}$.

\subsection{Aplicação do BAP}

Duas formas de aplicação foram utilizadas: Imersão, como utilizado por de Shimomura; Fujihara (1980), de $1 \mathrm{~cm}$ de parte apical dos cladódios por 24 horas, sendo necessários 1,5 litros de solução de BAP para formar uma lâmina de $1 \mathrm{~cm}$ na bandeja utilizada, totalizando 6,0 litros de solução com as concentrações com BAP e testemunha sem o fitorregulador.

Outro método de aplicação foi adaptado do método usado para a propagação rápida da bananeira (MENEGUCCI et al., 1995) com uso de seringa de $1 \mathrm{ml}$ da solução utilizando-se um estilete para afastar a parte próxima ao cilindro vascular até formar um sulco que a deposição da solução sem extravasar conforme ilustrado na Figura 1. Sendo necessários $60 \mathrm{ml}$ nas concentrações de BAP para a aplicação mais $20 \mathrm{ml}$ de água destilada para a testemunha.

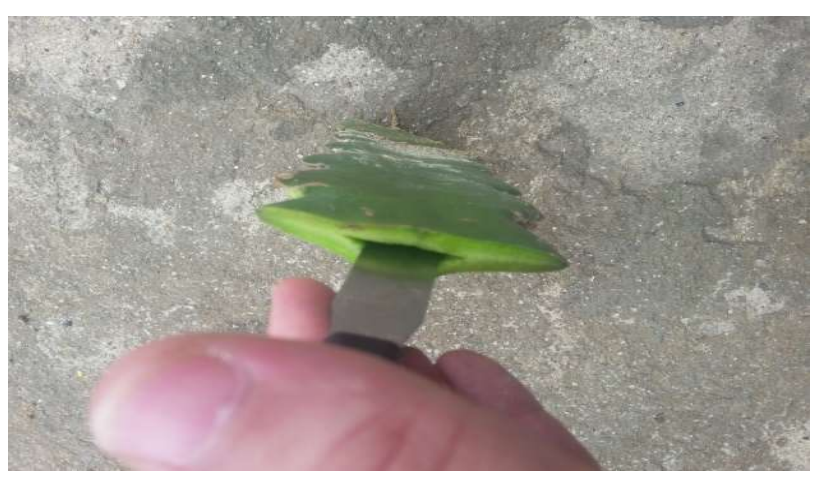

Figura 1. Corte no ápice da estaca de pitaia para aplicação de BAP. Figure 1. Cutting on the apex of the pitaya for BAP application.

\subsection{Plantio e tratos culturais}

A estaquia foi realizada no canteiro na profundidade de 1 $\mathrm{cm}$ como recomenda por Marques et al. (2012). Fez-se o sombreamento do canteiro com telado reduzindo a intensidade luminosa em 50\% como recomendado por Chang et al. (2016). Capinas manuais e irrigação com 10 litros água foram realizadas semanalmente. A poda aos 100 e 200 dias foi realizada com tesoura de poda rente aos cladódios primários

\subsection{Avaliações}

Aos 100 dias após o plantio (DAP) avaliou-se a sobrevivência (S), o número de brotações emitidas (NB), a soma do comprimento das brotações (CB), a massa fresca das brotações (MFB) e massa seca das brotações (MSB).

Para a avaliação da sobrevivência foi considerado como viva toda a estaca com sua coloração verde e que emitiram raízes. Considerou-se com brotação emitida toda a brotação maior que $1 \mathrm{~cm}$ de comprimento. A soma do comprimento das brotações foi realizada medindo-se cada brotação com régua milimétrica. A massa fresca das brotações mensurou-se com ajuda de balança digital e obteve-se a massa seca após secagem em estufa de ventilação forçada a 65 graus Célsius por 72 horas.

Aos 200 dias DAP avaliou-se os mesmos parâmetros para avaliar o efeito do BAP na rebrota da pitaia, classificados aqui como sobrevivência da rebrota (SR), número de rebrotações (NBR), soma do comprimento das rebrotações (CBR), massa fresca das rebrotações (MFR) e massa seca das rebrotações (MSR).

\subsection{Delineamento estatístico}

O delineamento utilizado foi inteiramente casualizado (DIC), com 4 repetições, em esquema fatorial $2 \times 4$, sendo 2 métodos de inoculação (imersão por 24 horas e aplicação) e quatro concentrações de $\operatorname{BAP}\left(0,50,100\right.$ e $\left.150 \mathrm{mg} \mathrm{L}^{-1}\right)$. Cada repetição teve 5 estacas, totalizando 160 estacas. $\mathrm{O}$ modelo estatístico considerado então foi:

$$
\hat{\mathrm{y}}=m+a_{i}+b_{j}+a b_{i j}+e_{i j}
$$

em que: $\hat{y}_{i j}=$ é o valor observado na unidade experimental; $m=$ é a média geral;; $\mathrm{a}_{\mathrm{i}}=$ é o efeito do $\mathrm{i}$-ésimo $(\mathrm{i}=1,2)$ método de inoculação do BAP; $b_{j}=$ é o efeito da j-ésima $(j=1,2, \ldots 4)$ dose 
de BAP; $(\mathrm{ab})_{\mathrm{ij}}=$ é o efeito da interação entre o i-ésimo método de inoculação de BAP e a j-ésima dose de BAP; $\mathrm{e}_{\mathrm{ij}}=$ é o efeito do erro a na parcela que recebeu o i-ésimo método de aplicação, j-ésimo dose de BAP (erro a).

Foram estudas os pontos de máximo das equações significativas por meio de suas derivadas e obtiveram-se, em cada parâmetro, os valores das doses de melhor reposta.

Foi realizada avaliação da homogeneidade das variâncias dos erros pelo Teste de Bartlett e da normalidade pelo Teste de Shapiro-Wilk. Os dados foram submetidos à análise de variância (ANOVA), o fator quantitativo (doses de BAP) foi decomposto (regressão linear, regressão quadrática e resíduos) e posteriormente estimados os valores dos coeficientes das regressões significativa e respectivos gráficos.

\section{RESULTADOS}

Os dados avaliados apresentaram homogeneidade das variâncias $(p>0,05)$ e aderência à distribuição normal $(p>0,05)$ requisitos para as análises de variâncias (ANOVA) e regressões apresentadas.

\subsection{Sobrevivência}

Todas as estacas apresentaram-se vivas aos 100 DAP e aos 200 DAP. $100 \%$ das estacas emitiram raízes.

\subsection{Número de brotações}

A análise de variância (Tabela 1) mostrou que existe um comportamento linear significativo $(\mathrm{p}<0,05)$ entre a dose de BAP (6-benzilaminopurina) e o número de brotações emitidas por estaca. Não houve diferenças estatísticas entre os métodos de inoculação de BAP e não houve interação entre os métodos de aplicação e Doses de BAP.

A regressão apresentou coeficiente linear de 0,0125 (Figura 2) significativo $(\mathrm{p}<0,05)$ e intercepto de 5,125 . As médias do número de brotações foram de 5,12; 5,75; 6,37 e 7,0 brotações, respectivamente, para as doses de $0,50,100$ e 150 mg L ${ }^{-1}$ de BAP. Um aumento de 0,$63 ; 1,25$ e 1,87 brotações por estaca em relação à testemunha $\left(0 \mathrm{mg} \mathrm{L}^{-1}\right.$ de BAP).

Tabela 1. Análise de variância do Número de Brotações Emitidas por estaca (NB) do fatorial (2X4) Métodos de inoculação e Doses de 6Benziloaminopurina (BAP).

Table 1. Variance Analysis of the Number of Ledger Sprouts (NB) of factorial (2X4) Inoculation Methods and 6-Benzylaminopurine Doses (BAP).

\begin{tabular}{llllll}
\hline FV & SQ & GL & QM & F & Valor-P \\
\hline Método & 1,13 & 1 & 1,13 & 0,44 & 0,51 \\
Doses & 20,13 & $(3)$ & 6,71 & 2,62 & $0,07(\mathrm{q})$ \\
R linear & 15,63 & 1 & 15,63 & 6,10 & $0,02 *$ \\
R quadrática & 2,00 & 1 & 2,00 & 0,78 & 0,38 \\
Residuos & 2,50 & 1 & 2,50 & 0,98 & 0,33 \\
Interações & 9,13 & 3 & 3,04 & 1,19 & 0,33 \\
Erro & 61,50 & 24 & 2,56 & & \\
Total & 91,88 & 31 & & & \\
\hline
\end{tabular}

$\overline{\mathrm{CV}}(\%)=26,40 . \mathrm{q}=$ dados quantitativos. $*$ significativo $(\mathrm{p}<0,05) . \quad \mathrm{FV}=$ Fonte de Variação, $\mathrm{SQ}=$ Soma dos Quadrados, $\mathrm{GL}=$ Graus de Liberdade, $\mathrm{MQ}=$ Quadrados Médios, F= Teste F, Valor $\mathrm{P}=$ Probabilidade, $\mathrm{CV}=$ Coeficiente de Variação, R Linear= Regressão Linear, R Quadrática= Regressão Quadrática.

\subsection{Comprimento das brotações}

A análise de variância (Tabela 2) mostrou que existe um comportamento quadrático significativo $(\mathrm{p}<0,01)$ entre a dose de BAP (6-benzilaminopurina) e a soma do comprimento das brotações emitidas. Não houve diferenças estatísticas entre os métodos de inoculação de BAP e não houve interação entre os métodos de aplicação e Doses de BAP.

A regressão quadrática é significativa $(\mathrm{p}<0,01)$, explicando o comportamento dos dados de CB (Figura 3 ) que foi crescente até o ponto de máximo de $78,7 \mathrm{mg} \mathrm{L}^{-1}$. Com valor de 0,0103 (negativo) para o coeficiente quadrático e 1,6213 (positivo) para o coeficiente linear.

A regressão retorna os valores de 189,42 cm, 244,73 cm, $248,55 \mathrm{~cm}$ e $200,86 \mathrm{~cm}$ para os valores de CB para as doses de $0,50,100$ e $150 \mathrm{mg} \mathrm{L}^{-1}$ de BAP, respectivamente. Por conseguinte, ocorreram aumentos de $55,31 \mathrm{~cm}, 59,13 \mathrm{~cm} \mathrm{e}$ $11,44 \mathrm{~cm}$ em relação à testemunha $\left(0 \mathrm{mg} \mathrm{L}^{-1}\right.$ de BAP) nas doses avaliadas. No ponto de máximo o $\mathrm{CB}$ foi de $253,22 \mathrm{~cm}$.

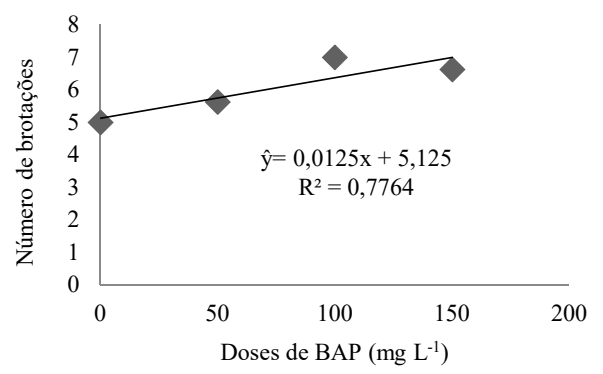

Figura 2. Regressão Linear do Número de Brotações Emitidas (NB) em função da dose de 6-Benziloaminopurina (BAP) inoculada. Figure 2. Linear regression of the Number of Buds Issued (NB) as a function of the dose of inoculated 6-Benzyloaminopurine0 (BAP).

Tabela 2. Análise de Variância da Soma do Comprimento das Brotações (CB) do fatorial (2X4) Métodos de inoculação e Doses de 6-Benziloaminopurina (BAP).

Table 2. Analysis of Variance of the Sum of the Sprouting Length (CB) of the factorial (2X4) Methods of inoculation and 6Benzylaminopurine Doses (BAP).

\begin{tabular}{llllll}
\hline FV & SQ & GL & QM & F & Valor-P \\
\hline Método & 836 & 1 & 836,40 & 0,51 & 0,48 \\
Doses & 26008 & $(3)$ & 8669,55 & 5,28 & $0,006(\mathrm{q})$ \\
R linear & 533 & 1 & 533,18 & 0,32 & 0,57 \\
R quadrática & 21308 & 1 & 21308,8 & 12,98 & $0,001^{* *}$ \\
Residuos & 4166 & 1 & 4166,59 & 2,54 & 0,12 \\
Interações & 7800 & 3 & 2600,19 & 1,58 & 0,21 \\
Erro & 39396 & 24 & 1641,52 & & \\
Total & 74042, & 31 & & &
\end{tabular}

$\mathrm{CV}(\%)=18,77 . \mathrm{q}=$ dados quantitativos. ${ }^{* *}$ significativo $(\mathrm{p}<0,01)$. FV= Fonte de Variação, $\mathrm{SQ}=$ Soma dos Quadrados, $\mathrm{GL}=$ Graus de Liberdade, $\mathrm{MQ}=$ Quadrados Médios, $\mathrm{F}=$ Teste F, Valor $\mathrm{P}=$ Probabilidade, $\mathrm{CV}=$ Coeficiente de Variação, R Linear= Regressão Linear, R Quadrática= Regressão Quadrática.

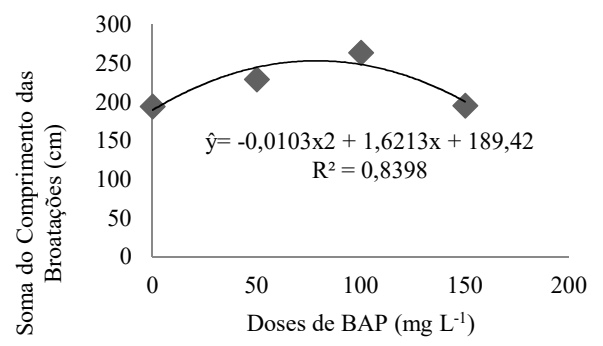

Figura 3. Regressão Quadrática do Soma do Comprimento das Brotações (CB) em função da dose de 6-Benziloaminopurina (BAP) inoculada.

Figure 3. Quadratic Regression of Bud Spreads Length (CB) as a function of inoculated 6-Benzylaminopurine (BAP) dose. 


\subsection{Massa fresca das brotações}

A análise de variância (Tabela 3) mostrou que existe um comportamento quadrático significativo $(p<0,01)$ entre a dose de BAP (6-benzilaminopurina) e a Massa Fresca das brotações emitidas. Não houve diferenças estatísticas entre os métodos de inoculação de BAP e não houve interação entre os métodos de aplicação e Doses de BAP.

Tabela 3. Análise de Variância da Massa Fresca das Brotações (MFB) do fatorial (2X4) Métodos de inoculação e Doses de 6Benziloaminopurina (BAP).

Table 3. Analysis of Variance of Fresh Sprout Mass (MFB) of factorial (2X4) Inoculation Methods and 6-Benzylaminopurine Doses (BAP).

\begin{tabular}{llllll}
\hline FV & SQ & GL & QM & F & Valor-P \\
\hline Método & 9494,42 & 1 & 9494 & 1,27 & 0,27 \\
Doses & 102503,8 & $(3)$ & 34167 & 4,58 & $0,01(\mathrm{q})$ \\
R linear & 8682,07 & 1 & 8682 & 1,16 & 0,29 \\
R quadrática & 90449,38 & 1 & 90449 & 12,14 & $0,001 * *$ \\
Resíduos & 3372,38 & 1 & 3372 & 0,45 & 0,50 \\
Interações & 7979,74 & 3 & 2659 & 0,36 & 0,78 \\
Erro & 178871,4 & 24 & 7452 & & \\
Total & 298849,4 & 31 & & &
\end{tabular}

$\mathrm{CV}(\%)=23,77 . \mathrm{q}=$ dados quantitativos. $^{* *}$ significativo $(\mathrm{p}<0,01) . \mathrm{FV}=$ Fonte de Variação, $\mathrm{SQ}=$ Soma dos Quadrados, $\mathrm{GL}=$ Graus de Liberdade, $\mathrm{MQ}=$ Quadrados Médios, F= Teste F, Valor $\mathrm{P}=$ Probabilidade, $\mathrm{CV}=$ Coeficiente de Variação, $\mathrm{R}$ Linear= Regressão Linear, $\mathrm{R}$ Quadrática= Regressão Quadrática.

A regressão quadrática é significativa $(\mathrm{p}<0,01$ explicando o comportamento dos dados de MFB (Figura 4), que foi crescente até o ponto de máximo de $81,8 \mathrm{mg} \mathrm{L}^{-1}$. Com valor de 0,0213 (negativo) para o componente quadrático e 3,4846 (positivo) para o coeficiente linear.

A regressão retorna os valores de 276,93 g, 397,91 g, 412,39 g e 320,37 g para os dados de MFB nas doses de 0, 50, 100 e $150 \mathrm{mg} \mathrm{L}^{-1}$ de BAP, respectivamente. Por conseguinte, ocorreram aumentos de 120,98 g, 135,46g e 43,44 g em relação à testemunha $\left(0 \mathrm{mg} \mathrm{L}^{-1} \mathrm{de} \mathrm{BAP}\right)$. No ponto de máximo a MFB foi de 419,45 g.

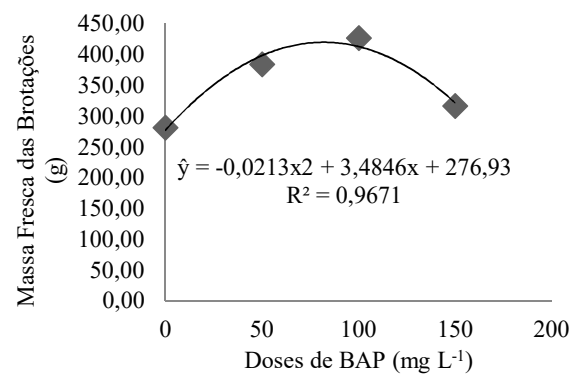

Figura 4. Regressão Quadrática da Massa Fresca das Brotações (MFB) em função da dose de 6-Benziloaminopurina (BAP) inoculada.

Figure 4. Quadratic Regression of Fresh Sprout Mass (MFB) as a function of inoculated 6-Benzylaminopurine (BAP) dose.

\subsection{Massa seca das brotações}

A análise de variância (Tabela 4) mostrou que existe um comportamento quadrático significativo $(\mathrm{p}<0,01)$ entre a dose de BAP (6-benzilaminopurina) e a Massa Seca das brotações emitidas. Não houve diferenças estatísticas entre os métodos de inoculação de BAP e não houve interação entre os métodos de aplicação e Doses de BAP.

A regressão quadrática foi significativa $(p<0,01)$, explicando o comportamento dos dados de MSB (Figura 5) que foi crescente até o ponto de máximo de $78,42 \mathrm{mg} \mathrm{L}^{-1}$. Com valor de 0,0024 (negativo) para o componente quadrático e 0,3764 (positivo) para o coeficiente linear.

A regressão retorna os valores de 50,34 g, 63,16 g, 63,98 g e 52,80 g para os valores de MSB nas doses de 0, 50, 100 e $150 \mathrm{mg} \mathrm{L}^{-1}$ de BAP respectivamente, aumentos de $12,82 \mathrm{~g}$, $13,64 \mathrm{~g}$ e $2,46 \mathrm{~g}$ em relação à testemunha $\left(0 \mathrm{mg} \mathrm{L}^{-1} \mathrm{de} \mathrm{BAP}\right)$. No ponto de máximo a MSB foi de 65,09 .

Tabela 4. Análise de Variância da Massa Seca das Brotações (MSB) do fatorial (2X4) Métodos de inoculação e Doses de 6Benziloaminopurina (BAP).

Table 4. Analysis of Variance of Dry Sprouting Mass (MSB) of factorial (2X4) Methods of inoculation and 6-Benzylaminopurine Doses (BAP).

\begin{tabular}{llllll}
\hline FV & SQ & GL & QM & F & Valor-P \\
\hline Método & 45,09 & 1 & 45,09 & 0,51 & 0,48 \\
Doses & 1401,95 & $(3)$ & 467,32 & 5,28 & $0,006(\mathrm{q})$ \\
R linear & 28,74 & 1 & 28,74 & 0,32 & 0,57 \\
R quadrática & 1148,62 & 1 & 1148,6 & 12,9 & $0,001^{* *}$ \\
Resíduos & 224,59 & 1 & 224,59 & 2,54 & 0,12 \\
Interações & 420,48 & 3 & 140,16 & 1,58 & 0,21 \\
Erro & 2123,60 & 24 & 88,48 & & \\
\hline
\end{tabular}

Total

$3991,12 \quad 31$

$\mathrm{CV}(\%)=16,69 . \mathrm{q}=$ dados quantitativos. $* *$ significativo $(\mathrm{p}<0,01) . \mathrm{FV}=$ Fonte de Variação, $\mathrm{SQ}=$ Soma dos Quadrados, $\mathrm{GL}=$ Graus de Liberdade, $\mathrm{MQ}=$ Quadrados Médios, $\mathrm{F}=$ Teste $\mathrm{F}$, Valor $\mathrm{P}=$ Probabilidade, $\mathrm{CV}=$ Coeficiente de Variação, R Linear= Regressão Linear, R Quadrática= Regressão Quadrática

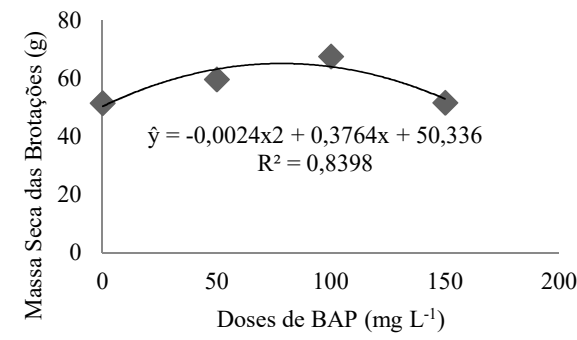

Figura 5. Regressão Quadrática da Massa Seca das Brotações (MSB) em função da dose de 6-Benziloaminopurina (BAP) inoculada. Figure 5. Quadratic Regression of Sprouting Dry Mass (MSB) as a function of inoculated 6-Benzyloaminopurine (BAP) dose.

\subsection{Rebrota}

A análise de variância dos dados da rebrota obtidos após 100 dias após a poda das brotações iniciais (200 DAP) não mostrou diferenças significativas $(\mathrm{p}>0,05)$ para nenhum dado avaliado (Número de rebrotações-NBR, Comprimento das rebrotações-CBR, Massa fresca das rebrotações-MFR, Massa seca das rebrotações-MSR).

\section{DISCUSSÃO}

\subsection{Sobrevivência}

A alta sobrevivência observada neste trabalho corrobora com os resultados de outros autores (MARQUES et al., 2012) e relaciona-se intrinsicamente com a rusticidade, acúmulo tecidual de água e nutrientes, capacidade de emissão de brotações e raízes adventícias e o mecanismo fotossintético que a pitaia apresenta. As adaptações anatômicas, morfológicas e metabólicas incluem o caule modificado fotossintetizante, folhas modificadas em forma de espinhos, presença de ceras e camada cuticular espessa que conferem a planta baixas taxas transpiratórias e altas taxas de 
aproveitamento de nutrientes (FAN et al., 2013; NIE et al., 2015).

Fachinello et al. (2005) e Almeida et al. (2014) citam a reserva de nutrientes, carboidratos e água como sendo primordial para o sucesso da propagação vegetativa. Esses nutrientes serão responsáveis por suprirem os processos de desdiferenciação, diferenciação e desenvolvimento de raízes adventícias na propagação por estaquia.

A rota fotossintética do tipo CAM (Metabolismo Ácido das Crassuláceas) e a plasticidade na regulação dessa rota (CAM cíclico e CAM idle) que a pitaia possui, contribuem para as altas taxas de sobrevivência das estacas de pitaia na propagação vegetativa, pois essas adaptações permitem altas taxas de assimilação de $\mathrm{CO}_{2}$ e inclusive o aproveitamento do $\mathrm{CO}_{2}$ da respiração mitocondrial (ORTIZ-HERNANDEZ et al., 1999).

Extrinsecamente relaciona-se com os fatores climáticos, edáficos, ausência de pragas, patógenos e ervas daninhas. Chang et al. (2016) citam que a pitaia é prejudicada quando altas temperaturas e taxas de luminosidade incidem sobre o cacto causando injúrias até a morte da planta. Neste trabalho altas taxas de insolação foram evitadas com a cobertura do canteiro com tela com potencial de redução de $50 \%$ na incidência solar. Não foram observados insetos no canteiro, nem doenças nas estacas de pitaia e as ervas daninhas que eventualmente surgiram foram controladas manualmente.

\subsection{Número de brotações}

Acréscimos no número de brotações emitidas em razão da aplicação de citocinina também foram observados por Shimomura; Fujihara (1980). Esses autores trabalharam com a estaquia de segmentos de 7,0 centímentros de $H$. trigonus e relataram que ao aplicar por imersão 25 g.L $\mathrm{L}^{-1}$ a $100 \mathrm{mg} \mathrm{L}^{-1} \mathrm{da}$ citocininaBenziladenina (BA) houve aumento de 1,6 a 2,8 no número de brotações emitidas.

Vários autores relatam que o uso de BAP na cultura de tecidos in vitro induziu número maior de brotações adventícias na micropropagação de pitaia (MENEZES et al., 2012; FAN et al., 2013).

A explicação biológica do efeito da citocinina na indução de brotações que explica os resultados obtidos no aumento do número de brotações na estaquia da pitaia com o uso do fitorregulador BAP é que as citocininas agem em conjunto com outros hormônios vegetais e estimulam a divisão (mitose) e diferenciação celular. A partir desses processos citocínicos essas células podem ser transformadas em órgãos do vegetal (morfogênese). As citocininas estão envolvidas também na quebra de dominância apical em gemas axilares e apicais com consequente indução de brotações (SHANI et al., 2010; TAIZ ZEIGER, 2013; MURAI, 2014; HARTMANN et al., 2017).

\subsection{Comprimento das brotações}

Shimomura; Fujihara (1980) observaram, assim como evidenciado neste trabalho, que a aplicação de citocinina proporciona o aumento no comprimento das brotações. Estes autores trabalharam com citocinina BA inoculadas por imersão da parte apical por 24 horas em estacas de $7 \mathrm{~cm}$ de $H$. trigonus e obtiveram brotações com comprimento de $35 \mathrm{~mm}$ a $65 \mathrm{~mm}$ (25 mg L $\mathrm{m}^{-1}$ a $100 \mathrm{mg} \mathrm{L}^{-1}$ de BA) contra 12,5 mm do controle (água destilada). Menezes et al. (2012) utilizando BAP e cinetina na micropropagação de pitaia verificaram a concentração de $10 \mathrm{mg} \mathrm{L}-1$ proporcionou menores tamanhos da parte aérea in vitro. Outros fatores podem influenciar o comprimento da parte aérea como o substrato utilizado (CORREIA et al., 2016) e o tamanho e número de gemas na estaca original.

A citocinina estimula o crescimento de tecidos meristemáticos e a expressão de promotores de citocinese (MURAI, 2014) o que pode ter contribuído para os resultados observados no presente trabalho. A aplicação exógena de citocinina promove a atividade fotossintética pelo aumento de conteúdo foliar de clorofilas acelerando o desenvolvimento de cloroplastos ou modulando a atividade de enzimas fotossintéticas (PIMENTEL, 1998; ZWAC; RASHOTTE, 2013).

Considera-se o comprimento das brotações um aspecto importante economicamente, pois as estacas de pitaia são vendidas no mercado segmentadas e autores indicam que estacas de 15 a $25 \mathrm{~cm}$ como ideais para o processo de estaquia (MARQUES et al., 2011).

\subsection{Massa fresca das brotações}

Como evidenciado neste trabalho, Menezes et al. (2014) também observaram na micropropagação da pitaia o aumento de massa fresca quando inoculado ANA, BAP ou cinetina ao meio MS nas concentrações de $\left(0,1 \mathrm{mg} \mathrm{L}^{-1}\right.$ de ANA e 1 ou 5 $\mathrm{mg} \mathrm{L}^{-1}$ de BAP ou cinetina em relação ao controle meio MS sem adição de fitorreguladores e não significância quando aplicado $10 \mathrm{mg} \mathrm{L}^{-1}$ de BAP ou cinetina ao meio.

$\mathrm{O}$ aumento da massa fresca da parte aérea de pitaia por causa do uso de fitorreguladores foi observado por Pontes Filho et al. (2014) que utilizou AIB na estaquia dessa frutífera.

Murai (2014) relata a influência da citocinina no crescimento de zonas meristemáticas, e segundo esse autor e Pimentel (1998) a distribuição de citocininas é controlada pelos ápices vegetativos que redirecionam o fluxo de assimilados. Essa variação pode explicar o aumento do número de brotações, seus comprimentos e consequente aumento de peso de massa fresca que foram observados neste trabalho.

\subsection{Massa seca das brotações}

Pesquisadores verificaram o aumento da matéria seca quando utilizado fitorreguladores na estaquia da pitaia (SHIMOMURA; FUJIHARA, 1980; PONTES FILHO et al., 2014) corroborando com os dados observados neste trabalho. Shani et al. (2010) relatam o efeito das citocininas no aumento da citocinese e consequente aumento e crescimento das regiões meristemáticas. Oliveira et. al, (2008) trabalhando com Annona glabra citam o efeito a citocinina aplicada em áreas foliares no aumento da quantidade de clorofila e cloroplastos. Soares et al. (2017) aplicaram citocinina em plantas de Glycinemax relatam o aumento dos níveis da enzima nitrato redutase e aumento da eficiência de absorção de nitrogênio. Esses incrementos podem explicar o aumento na matéria seca por permitir a planta de pitaia o maior acúmulo de esqueletos de carbono. O aumento observado na matéria seca também pode estar relacionado ao maior número de cladódios que possuem função fotossintética nos cactos.

Os decréscimos verificados nos dados de CB, MFB e MSB para as concentrações de BAP acima do ponto de máximo nas regressões podem estar relacionadas à alta concentração de fitorregulador que causa desequilíbrio em diversos processos metabólicos causando o declínio no crescimento como é observado, por exemplo, em fitorreguladoresauxínicos (TAIZ; ZEIGER, 2013). 


\subsection{Rebrota}

A não significância estatística observadas nos dados avaliados corrobora fisiologicamente com os processos regulação hormonal da citocinina. As citocininas podem ser convertidas em radicais (nucleotídeos ou glicosídeos), conjugadas com glicose ou outros açúcares e serem catabolizadas pela ação oxidante de citocinina-oxidase (BARRUETO CID, 2000; TAIZ; ZEIGER, 2013, MURAI, 2014). Esses processos de regulação podem explicar o efeito imediato quando as citocininas são aplicadas de forma exógena.

\section{CONCLUSÕES}

Os métodos de aplicação da citocinina BAP utilizados não interferem na ação deste fitorregulador, assim, para economizar solução, recomenda-se fazer a aplicação da citocinina por meio de corte na parte apical nas estacas de pitaia.

Dentro dos limites de concentrações adotadas, a aplicação da citocinina BAP promove incremento linear do número de brotações emitidas pelas estacas de pitaieira. $\mathrm{O}$ comportamento quadrático para os parâmetros: tamanho, peso fresco e seco das brotações indica que a concentração ideal de BAP encontra-se próxima de $80 \mathrm{mg} \mathrm{L}^{-1}$. A aplicação de BAP não altera o número, comprimento, peso fresco e seco das rebrotações.

\section{REFERÊNCIAS}

ALMEIDA, E. I. B; CORRÊA, M. C. M; CAJAZEIRA, J. P.; QUEIROZ, R. F; BARROSO, M. M. A.; MARQUES, V. B. Cultivo de Hylocereus sp. com enfoque na propagação vegetativa e adubação mineral. Revista Agroambiente, Boa Vista, v. 10, n. 1, p. 65-76, jan./mar. 2016. DOI: http://dx.doi.org/10.18227/1982-8470ragro.v10i1.2823

ALMEIDA, E. I. B; CORREAA, M. C. M; CRISOSTOMO, L. A.; ARAÚJO, N. A.; DO VALE SILVA, J. C. Nitrogênio e Potássio no crescimento de mudas de pitaia [Hylocereus undatus (Haw.) Britton \& Rose]. Revista Brasileira de Fruticultura, Jaboticabal, v. 36, n. 4, p. 1018-1027, dez. 2014. DOI: http://dx.doi.org/10.1590/0100-2945-296/13

ANTUNES, L. F. S.; SCORIZA, R. N.; SILVA, D. G.; CORREIA, M. E. F. Production and efficiency of organic compost generated by millipede activity. Ciência Rural, Santa Maria, v. 46, n. 5, p. 815-819, mar. 2016. DOI: http://dx.doi.org/10.1590/0103-8478cr20150714

BARRUETO CID, L. P. Introdução aos hormônios vegetais. Brasília: Embrapa Recursos Genéticos e Biotecnologia, 2000. $180 \mathrm{p}$.

BOTIN, A. A; CARVALHO, A. Reguladores de crescimento na produção de mudas florestais. Revista de Ciências Ambientais, Alta Floresta, v. 13, n. 1, p. 83-96, jan. 2015.

CHANG, P-T.; HSIEH, C-C.; JIANG, Y-L. Responses of 'Shih Huo Chuan' pitaya (Hylocereus polyrhizus (Weber) Britt. \& Rose) to different degrees of shading nets. Scientia Horticulturae, Amsterdam, v. 198. n. 1, p. 154162, jan. $2016 . \quad$ DOI: https://dx.doi.org/10.1016/j.scienta.2015.11.024

CORREIA, D.; NASCIMENTO, E. H. S.; MORAIS, J. P. S. Crescimento de mudas de pitaya (Hylocereus polyrhizus Weber Britton e Rose) em diferentes substratos. 1. ed. Fortaleza: Embrapa Agroindústria Tropical, maio 2016. (Boletim de Pesquisa e Desenvolvimento, 115)
FACHINELLO, J.C.; HOFFMANN, A.; NACHTIGAL, J.C. Propagação de Plantas frutíferas. Brasília: Embrapa Informação Tecnológica, 2005. $221 \mathrm{p}$.

FAN Q. J., ZHENG S. C., YAN F. X., ZHANG B. X., QIAO G., WEN X. P. Efficient regeneration of dragon fruit (Hylocereus undatus) and an assessment of the genetic fidelity of in vitro: derived plants using ISSR markers. Journal Horticulture Science Biotechnology, London, v. 88 , n. 5, p. 631-637, nov. 2013. DOI: https://dx.doi.org/10.1080/14620316.2013.11513017

FERRERES, F.; GROSSO, C.; GIL-IZQUIERDO, A.; VALENTÃO, P.; MOTA, A. T.; ANDRADE, P. B. Optimization of the recovery of high-value compounds from pitaya fruit by products using microwave-assisted extraction. Food Chemistry, London, v. 230, n. 1, p. 463474, mar. 2017.2 DOI: https://dx.doi.org/10.1016/j.foodchem.2017.03.061

HARTMANN, H. T.; KESTER, D. E.; DAVIES JUNIOR, F. T.; GENEVE, R. L. Plant propagation: principles and practices. 9. ed. New Jersey: Prentice Hall, 2017.

HUA, Q. ;CHEN, P. ;LIU, W.; MA, Y.; LIANG, R.; WANG, L.; WANG, Z.; HU, G.; QIN, Y. A protocol for rapid in vitro propagation of genetically diverse pitaia. Plant Cell, Tissue and Organ Culture, Dordrecht, v. 120, n. 2, p.741745, out. 2015. DOI: https://dx.doi.org/10.1007/s11240014-0643-9

MARQUES, V. B.; MOREIRA, R. A.; RAMOS, J. D.; ARAUJO, N. A.; CRUZ, M. C. M. Tamanho de cladódios na produção de mudas de pitaia vermelha. Revista Caatinga, Mossoró, v. 24, n. 4, p. 50-54, out./dez. 2011.

MARQUES, V. B.; MOREIRA, R. A.; RAMOS, J. D.; ARAUJO, N. A.; CRUZ, M. C. M. Profundidade de plantio e dominância apical na estaquia da pitaia vermelha. Semina: Ciências Agrárias, Londrina, v. 33, n. 6, p. 2091 2098, nov./dez. $2012 . \quad$ DOI: http://dx.doi.org/10.5433/1679-0359.2012v33n6p2091

MENEGUCCI, J. L. P.; RESENDE; SILVA, C. R. de. Propagação in vivo da bananeira Prata: efeito de diâmetros de rizomas e doses de 6-benzilaminopurina. Ciência e Prática, Lavras, v. 19, n. 2, p. 171-175, abr./jun. 1995.

MENEZES, T. P.; GOMES, W. A.; PIO, L. A. S.; PASQUAL, M., RAMOS, J. D. Microprogação e endorreduplicação em pitaia vermelha, Hylocereus undatus HAW. Bioscience Journal, Uberlândia, v. 28, n. 6, p. 868-876, nov./dez. 2012.

MIZRAHI, Y. Vine-cacti pitayas: The new crops of the World. Revista Brasileira de Fruticultura, Jaboticabal, v. 36, n. 1, p. 124-138, mar. 2014. DOI: http://dx.doi.org/10.1590/0100-2945-452/13

NIE, Q.; LIGAO, G.; JIEFAN, Q.; QIAO, G.; PENGWEN, X.; TAOLIU; JUNPENG, Z.; QUIANGCAI, Y. Isolation and characterization of catalase gene "HuCAT3" from pitaya (Hylocereus undatus) and its expression under abiotic stress. Gene, v. 563, n. 1, p. 63-71, maio, 2015. DOI: https://dx.doi.org/10.1016/j.gene.2015.03.007

NUNES, E. N.; SOUSA, A. S. B.; LUCENA, C. M.; SILVA, S. M.; LUCENA, R. F. P.; ALVES, C. A. B.; ALVES, R. E. Pitaia (Hylocereus sp.): Uma revisão para o Brasil. Gaia Scientia, João Pessoa, v. 8, n . 1, p. 90-98, mar. 2014.

OLIVEIRA, L. M.; MAGDI, R. P.; ALOUFA, A. I.; CASTRO, E. M.; SANTANA, J. R. F.; NOGUEIRA, R. C. Efeitos de citocininas sobre a anotomia folhar e o crescimento de Annona glabra L. durante o cultivo in vitro 
e ex vitro. Ciência Rural, Santa Maria, v. 38, n. 5, p. 1447 1451, ago, 2008. DOI: http://dx.doi.org/10.1590/S010384782008000500040

ORTIZ-HERNANDEZ, Y. D.; LIVERA, M. M.; COLINAS L, M. T. B.; CARRILO-SALAZAR, J. A. Estrés hídrico e intercambio de $\mathrm{CO} 2$ de La pitahaya (Hylocere usundatus). Agrociencia, Chapingo, v. 33, n. 1, p. 397-405, out./dez. 1999.

ORTIZ-HERNANDEZ, Y. D.; CARRILO - SALAZAR, J. A. Pitaia (Hylocereus spp.: um revisão). Comunicata Scientiae, v. 3, n. 4, p. 220-237, dez. 2012.

PIMENTEL, C. Metabolismo do Carbono na Agricultura Tropical. Edur: Seropédica, 1998. 150 p.

PONTES FILHO, F. S. T.; ALMEIDA, E. I. B.; BARROSO, M. M. A.; CAJAZEIRA, J. P.; CORRÊA, M. C. M. Comprimento de estacas e concentrações de ácido indolbutírico (AIB) na propagação vegetativa de pitaia. Revista Ciência Agronômica, Fortaleza, v. 45, n. 4, p. 788-793, out./dez. 2014.

SHANI, E.; BEN-GERA, HADAS; SHLEIZER-BURKO, S.; BURKO, Y., WEISS, D.; ORI, N. Cytokinin regulates compounds leaf development in tomato. The plant cell, Rockville, v. 22, p. 3206-3217, out. 2010. DOI: https://dx.doi.org/10.1105/tpc.110.078253
SHIMOMURA, T.; FUJIHARA, K. Stimulation of axillary shoot formation of cuttings of Hylocereus trigonus (Cactaceae) by pre-soaking in benzyladenine solution. Scientia Horticulturae, v. 13, n. 3, p. 289-296, nov. 1980. DOI: https://dx.doi.org/10.1016/0304-4238(80)90068-0

SOARES, L. H.; DOURADO NETO, D.; FAGAN, E. B.; TEIXEIRA, W. F.; PEREIRA, I. S. Physiological, phenometric and productive changes in soybean crop due to the use of kinetin. Pesquisa Agropecuária Tropical, Goiânia, v. 47, n. 1, p. 80-86, jan-mar, 2017. DOI: http://dx.doi.org/10.1590/1983-40632016v4742790

TAIZ, L.; ZEIGER, E. Fisiologia Vegetal. 5. ed. Porto alegre: Artmed, 2013. $953 \mathrm{p}$.

VIÑAS, M.; FERNANDEZ -BRENES, M.; AZOFEIFA, A.; JIMENEZ, V. In vitro propagation of purple pitahaya (Hylocereus costaricensis [F.A.C. Weber] Britton \& Rose) cv. Cebra. In Vitro Cellular e Developmental BiologyPlant, Columbia, v. 48, n. 5, p. 469-477, maio 2012. DOI: https://dx.doi.org/10.1007/s1 1627-012-9439-y

ZWAC, P. J.; RASHOTTE, A. M. Cytokinin inhibition of leaf senescence. Plant Signaling \& Behavior, v. 8, n. 7, jul., 2013. DOI: https://dx.doi.org/10.4161/psb.24737 